\title{
Acute effects of selective serotonin reuptake inhibitors on neuroleptic-induced catalepsy in mice
}

J.G.P. Pires,

V. Bonikovski and H.A. Futuro-Neto
Departamento de Ciências Fisiológicas, Centro Biomédico, Universidade Federal do Espírito Santo, Vitória, ES, Brasil

\author{
Correspondence \\ J.G.P. Pires \\ Departamento de Ciências Fisiológicas \\ Centro Biomédico, UFES \\ Av. Marechal Campos, 1468 \\ 29040-090 Vitória, ES \\ Brasil \\ Fax: +55-27-3335-7330 \\ E-mail: jgppires@npd.ufes.br \\ Research partially supported by \\ CNPq (No. 300610/2003-3). \\ $\mathrm{V}$. Bonikovski was the recipient of \\ a M.Sc. scholarship from CAPES.
}

Received July 30, 2004 Accepted July 26, 2005

\begin{abstract}
Depression found in Parkinson disease (PD) usually responds to selective serotonin reuptake inhibitors (SSRIs). Drugs that modify experimental neuroleptic catalepsy (NC) might affect extrapyramidal symptoms in PD. Therefore, the effects of SSRIs on NC were tested in mice, 26-36 g, separated by sex. Catalepsy was induced with haloperidol ( $\mathrm{H} ; 1 \mathrm{mg} / \mathrm{kg}, i p)$ and measured at 30-min intervals using a bar test. An SSRI (sertraline, ST; paroxetine, PX; fluoxetine) or vehicle (C) was injected ip 30 min before H. Dunnett's test was used for comparison of means. ST (1-5 mg/kg) or PX (1-5 mg/kg) attenuated NC, with a similar inhibition found in both sexes $(5 \mathrm{mg} / \mathrm{kg}, 180 \mathrm{~min}$ : ST - males: $124 \pm 10$ vs $714 \pm 15$ s in C; females: $116 \pm 10$ vs $718 \pm 6$ s in C; PX - males: $106 \pm 10$ vs $714 \pm 14$ s in C; females: $102 \pm 10$ vs $715 \pm 14 \mathrm{~s}$ in C). At $0.3 \mathrm{mg} / \mathrm{kg}$, neither of these drugs affected NC. Fluoxetine (1$25 \mathrm{mg} / \mathrm{kg}$ ) also inhibited catalepsy, although the effect was not dosedependent; no differences were observed between males and females $(5 \mathrm{mg} / \mathrm{kg}, 180 \mathrm{~min}$ : males, $185 \pm 14$ vs $712 \pm 14 \mathrm{~s}$ in C; females, 169 \pm 10 vs $710 \pm 19 \mathrm{~s}$ in C). For these SSRIs, maximal inhibition of NC was obtained with $5 \mathrm{mg} / \mathrm{kg}, 180 \mathrm{~min}$ after $\mathrm{H}$. These results are consistent with the hypothesis that serotonergic mechanisms modulate nigrostriatal transmission, and suggest that SSRIs are possibly safe in depressive PD patients.
\end{abstract}

The phenomenon of cataleptic immobility induced in rodents by typical neuroleptics (e.g., haloperidol, chlorpromazine, fluphenazine) is a robust behavioral method for studying nigrostriatal function and its modulation by cholinergic, serotonergic, nitrergic, and other neurotransmitter systems $(1,2)$. There is some evidence that agents able to potentiate neuroleptic-induced catalepsy in rodents can intensify extrapyramidal symptoms in Parkinson disease; alternatively,
Key words

- Selective serotonin reuptake inhibitors

- Fluoxetine

- Sertraline

- Paroxetine

- Extrapyramidal system

- Catalepsy drugs which attenuate catalepsy might reduce (or, at least, not increase) the extrapyramidal signs $(3,4)$.

Although motor disturbances are crucial clinical findings in Parkinson disease, the patients commonly exhibit other associated conditions, including depression (5). Modern antidepressant agents, such as sertraline and other selective serotonin reuptake inhibitors (SSRIs), are frequently used to treat depressive conditions in these patients $(5,6)$. 
There are, however, contradictory reports concerning the safety of these drugs, particularly in elderly patients with Parkinson disease (6,7). In addition, as far as we know, the SSRIs have not been systematically tested in a model of neuroleptic-induced catalepsy.

The present study was designed to determine the acute effects of three different SSRIs (sertraline, paroxetine and fluoxetine) on mice. Since i) gender-related differences seem to be a common feature in the pharmacological properties of several centrally active drugs $(8,9)$; ii) there is evidence for sex differences in the serotonergic control of gonadotropins release (10), and iii) the extrapyramidal system is modulated by sex hormones $(2,11)$, the animals were separated by sex in order to detect any effect of gender on SSRIs acting on extrapyramidal function.

Experiments were performed on 60- to 80-day-old albino mice from our breeding stock, weighing 26-36 g, separated by sex at least 1 month before the experimental procedure. The mice were housed in same-sex pairs in plastic cages with sawdust bedding material, fed a standard rat chow and filtered water ad libitum, and were treated in accordance with the international guidelines for animal care. Female mice were tested without monitoring the estrous cycle, since the major interest of this study was to investigate the possibility that the SSRIs differentially affect male and female animals.

Drugs and suppliers were as follows: haloperidol (Haldol ${ }^{\circledR}$, Janssen, São Paulo, SP, Brazil), sertraline hydrochloride (Pfizer, São Paulo, SP, Brazil; kindly donated by Imafar Ltd., Vitória, ES, Brazil), paroxetine hydrochloride (Glaxo SmithKline, São Paulo, SP, Brazil), and fluoxetine hydrochloride (Sigma, St. Louis, MO, USA). Haloperidol was diluted from ampoules with saline $(0.9 \%$ $\mathrm{NaCl}$ ) and sonicated before use. The SSRIs were dissolved by sonication in saline. All drug solutions were freshly prepared.

Catalepsy was induced with haloperidol
$(1 \mathrm{mg} / \mathrm{kg}, \mathrm{ip})$ and measured at 30-min intervals by means of a standard bar test, with each animal being used only once. This dose of the neuroleptic drug was chosen to produce a moderate degree of catalepsy, so that either attenuation or potentiation of the phenomenon could be detected $(1,2)$. The drugs tested (and saline for the controls) were injected $i p$ with a $27.5-\mathrm{G}$ needle, in a volume of $\sim 3.5 \mathrm{ml} / \mathrm{kg}$ weight, $30 \mathrm{~min}$ before haloperidol.

Briefly, catalepsy was measured as the time the mouse maintained an imposed position with both front limbs extended and resting on a $3-\mathrm{cm}$ high wood bar $(0.9 \mathrm{~cm}$ in diameter). The end point of catalepsy was considered to occur when both front paws were removed from the bar or if the animal moved its head in an exploratory manner. A cut-off time of $720 \mathrm{~s}$ was applied. Between determinations, the animals were returned to their individual home cages. All observations were made between 9:00 and 17:00 $\mathrm{h}$ in a quiet room, at $23-26^{\circ} \mathrm{C}$.

Data are reported as means \pm SEM for 12 mice per group. For statistical purposes, the durations of catalepsy (expressed in seconds) were $\log$ transformed $[\ln (\mathrm{x}+1)]$, and significant differences were initially assessed by two-way ANOVA with repeated measures (treatment and time as factors). If significance was detected for treatment $\mathrm{x}$ time interactions, one-way ANOVA with repeated measures followed by the two-tailed Dunnett test was performed for each time point to determine differences between control and other experimental groups. The level of significance was set at $\mathrm{P}<0.05$.

Sertraline (1 or $5 \mathrm{mg} / \mathrm{kg}$ ip) significantly attenuated haloperidol-induced catalepsy in male mice (Figure 1A). Overall, this attenuation was more intense at the higher dose; however, a clear dose-dependence was only observed at 150 min after haloperidol, continuing thereafter. At the dose of $0.3 \mathrm{mg} / \mathrm{kg}$, sertraline did not change the duration of catalepsy compared to control (Figure 1A). 
A very similar pattern was observed in females acutely injected with sertraline (Figure 1B). In addition, the maximal percentage of inhibition of catalepsy was almost identical in males and females: 83 and $84 \%$, respectively (at $180 \mathrm{~min}$ after haloperidol). F values from ANOVA for factor A (treatment) were 477,383 (males) and 261,276 (females), while $\mathrm{F}$ values for A x B (treatment $\mathrm{x}$ time) interaction were 108,008 and 50,221 , respectively (in all cases, $\mathrm{P}<0.01$ ). An analogous pattern of effects was ob-
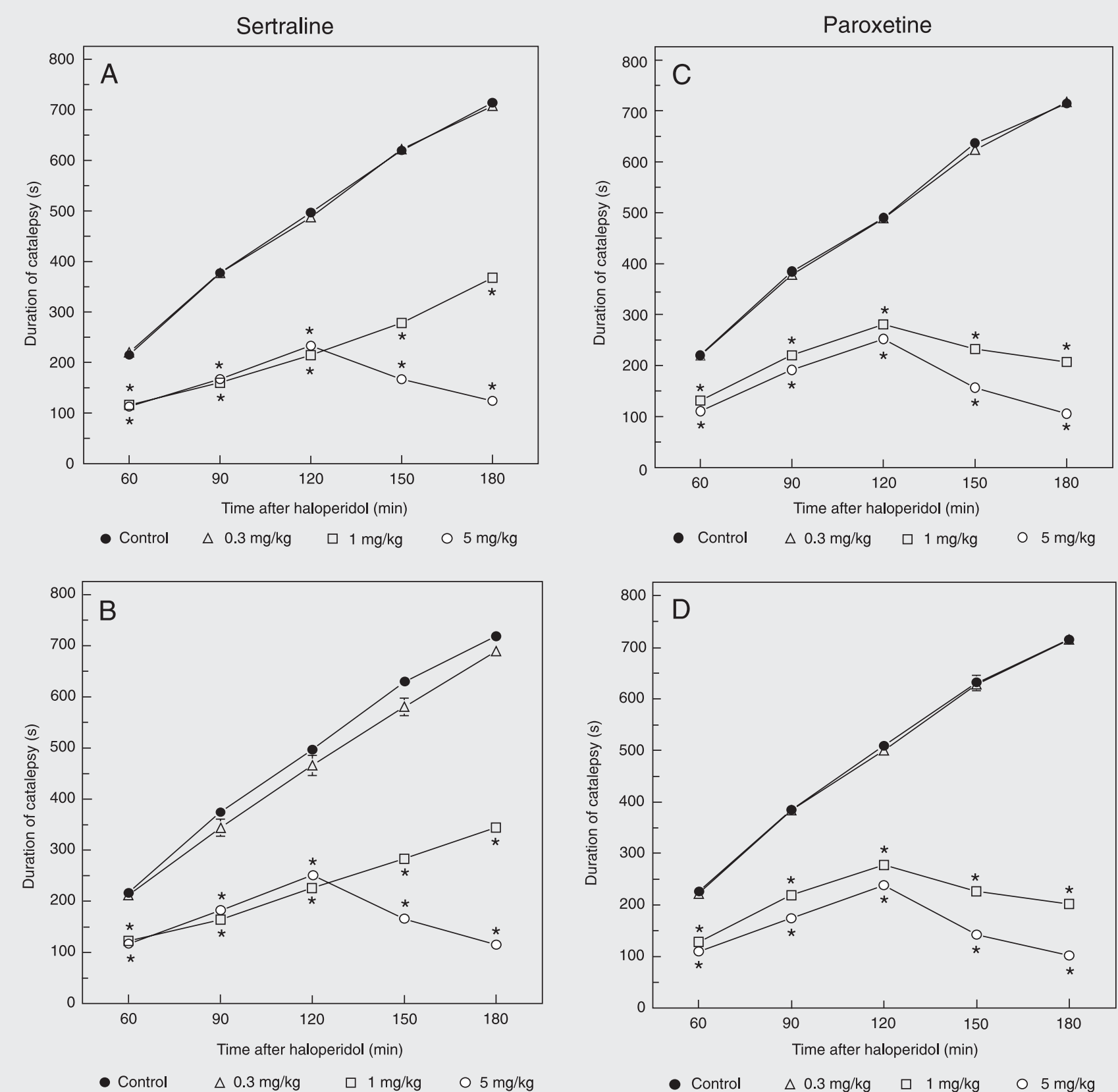

Figure 1. Effects of sertraline $(A, B)$ and paroxetine $(C, D)$ on haloperidol-induced catalepsy in male $(A, C)$ and female $(B, D)$ mice. The mice received $0,0.3,1.0$, and $5 \mathrm{mg} / \mathrm{kg}$, ip, of sertraline or paroxetine. Data are reported as means \pm SEM for 12 mice per group. ${ }^{*} \mathrm{P}<0.05$ compared to vehicle (Dunnett test). 
served with paroxetine. This drug, at 1 or 5 $\mathrm{mg} / \mathrm{kg}$ ip, also significantly reduced the intensity of catalepsy, both in males (Figure 1C) and females (Figure 1D), with the maximal attenuation being observed with $5 \mathrm{mg} /$
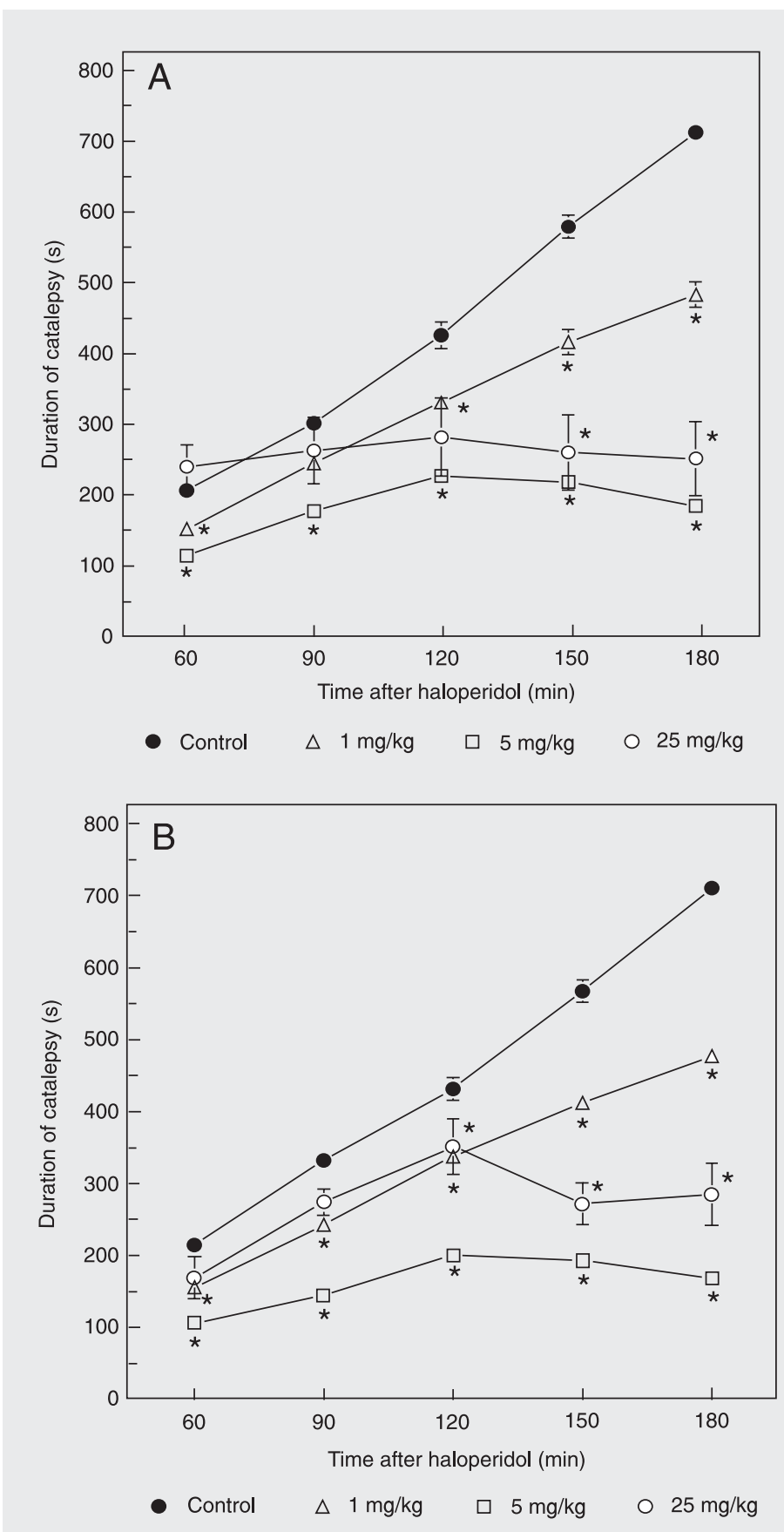

Figure 2. Effects of fluoxetine (1.0, 5.0, and $25 \mathrm{mg} / \mathrm{kg}$, ip) on haloperidol-induced catalepsy in male (A) and female (B) mice. Data are reported as means \pm SEM for 12 mice per group. ${ }^{*} \mathrm{P}<0.05$ compared to vehicle (Dunnett test). $\mathrm{kg}$ at 180 min after haloperidol (85 and $86 \%$ inhibition, respectively). $\mathrm{F}$ values from ANOVA for factor A (treatment) were 1,699.5 (males) and 2,387.6 (females), while $\mathrm{F}$ values for A x B interaction were 366,882 and 337,865 , respectively $(\mathrm{P}<0.01$ in all cases).

Fluoxetine was tested at the doses of 1.0, 5.0 and $25 \mathrm{mg} / \mathrm{kg}$. This SSRI also caused a reduction of catalepsy, which was similar in male and female mice (Figure 2). However, the effect was not dose-dependent, since maximal attenuation was found at the intermediate dose, i.e., $5 \mathrm{mg} / \mathrm{kg}$ (\% inhibition: 74 and $76 \%$, for males and females, respectively). F values from ANOVA for factor A (fluoxetine) were 21,355.7 (males) and $83,730.4$ (females), while values for drug $\mathrm{x}$ time interaction were 20,228 and 12,562, respectively (in all cases, $\mathrm{P}<0.01$ ).

It should be noted that the magnitude of catalepsy in the three control (saline) groups was similar in male and female animals.

The blockade of neuronal transport of serotonin (5-HT) by SSRIs occurs immediately and is long-lasting, leading to complex adaptive or secondary responses (12). These drugs cause an increase in synaptic availability of 5-HT, which interacts with a large number of receptor subtypes, including 5$\mathrm{HT}_{1 \mathrm{~A}}(12,13)$. Acute behavioral effects of SSRIs in rodents include both an increase (14) and a reduction (15) of locomotor activity, and the reasons for this discrepancy are not well understood. Previous studies from our laboratory have shown that clomipramine, a non-selective antidepressant, enhances the neuroleptic-induced catalepsy (16), while fluoxetine (at $5 \mathrm{mg} / \mathrm{kg}$ ip, in male mice) attenuates the phenomenon (17). The present results showed that, despite the pharmacological heterogeneity of the tested SSRIs (12), these drugs consistently attenuate the neuroleptic-induced catalepsy. This suggests that these drugs have a low propensity to cause extrapyramidal adverse effects in patients. As seen in the Introduction, the 
clinical literature reports some extrapyramidal symptoms associated with sertraline and other SSRIs (7). However, these effects seem to be quite infrequent, and a recent clinical study has shown that SSRIs do not significantly worsen extrapyramidal symptomatology in patients with Parkinson disease (18). The improvement of depressive symptoms in patients with Parkinson disease is most frequently obtained with antidepressant drugs (mainly SSRIs), although individual or family counseling might be helpful (5).

Since the central serotonergic system modulates nigrostriatal dopaminergic transmission (1), it is tempting to speculate that this reported anticataleptic effect of the SSRIs is related to desensitization of 5- $\mathrm{HT}_{1 \mathrm{~A}}$ receptors, a well-documented phenomenon (13). However, blockade of these receptors with the selective antagonist WAY 100135 enhanced haloperidol-induced catalepsy (19). On the other hand, it has been reported that 5 - $\mathrm{HT}_{3}$ receptor antagonists reduce neuroleptic-induced catalepsy (1); hence, the involvement of these receptors in the anticataleptic effect of SSRIs cannot be ruled out. Therefore, further studies are necessary to clarify the mechanism by which acute administration of SSRIs inhibits neuroleptic-induced catalepsy in rodents.

We did not find any relevant gender influence on the acute effects of SSRIs in this experimental model of nigrostriatal function. However, the female stage of the estrous cycle was not determined, which is a limitation of the present study. In addition, we cannot rule out that such influences are operative in a chronic context. For instance, there is evidence that $5-\mathrm{HT}_{1 \mathrm{~A}}$ receptors located in the hypothalamic areas controlling sexual behavior are influenced by the estrus cycle (20). To better resolve this issue and because these results could have implications for the medicinal use of the drugs, a future study employing controlled sampling of females in specific estrous stages should be performed. In addition, it is necessary to determine if differences in drug pharmacodynamics, pharmacokinetics or body fat underlie the absence of sex differences in the induced behavioral effects.

\section{References}

1. Silva SR, Futuro Neto HA \& Pires JGP (1995). Effects of $5-H T_{3}$ receptor antagonists on neuroleptic-induced catalepsy in mice. Neuropharmacology, 34: 97-99.

2. Pires JGP, Costa PG, Saraiva FP et al. (2003). Gender-related differences in the effects of nitric oxide donors on neurolepticinduced catalepsy in mice. Brazilian Journal of Medical and Biological Research, 36: 239-245.

3. Marti-Masso JF, Poza JJ \& Lopez de Munain A (1996). Drugs inducing or aggravating parkinsonism: a review. Therapie, 51: 568577.

4. Ossowska K (2002). Neuronal basis of neuroleptic-induced extrapyramidal side effects. Polish Journal of Pharmacology, 54: 299-312.

5. Sawabini KA \& Watts RL (2004). Treatment of depression in Parkinson disease. Parkinsonism and Related Disorders, 10 (Suppl 1): S37-S41.

6. Chung TH, Deane KHO, Ghazi-Noori S et al. (2003). Systematic review of antidepressant therapies in Parkinson disease. Parkinsonism and Related Disorders, 10: 59-65.

7. Lambert MT, Trutia C \& Petty F (1998). Extrapyramidal adverse effects associated with sertraline. Progress in Neuro-Psychopharmacology and Biological Psychiatry, 22: 741-748.
8. Pires JGP, Monteiro KC, Alvarenga SO et al. (1998). Evidence suggesting that gonadal hormones influence benzodiazepine withdrawal-induced weight loss in rats. Progress in Neuro-Psychopharmacology and Biological Psychiatry, 22: 425-433.

9. Beierle I, Meibohm B \& Derendorf H (1999). Gender differences in pharmacokinetics and pharmacodynamics. International Journal of Clinical Pharmacology and Therapeutics, 37: 529-547.

10. Becu de Villalobos D, Lux VA, Lacau de Mengido IM et al. (1984). Sexual differences in the serotonergic control of prolactin and luteinizing hormone secretion in the rat. Endocrinology, 115: 84-89.

11. Becker JB (1999). Gender differences in dopaminergic function in striatum and nucleus accumbens. Pharmacology, Biochemistry, and Behavior, 64: 803-812.

12. Baldessarini RJ (2001). Drugs and the treatment of psychiatric disorders. Depression and anxiety disorders. In: Hardman JG \& Limbird LE (Editors), Goodman \& Gilman's. The Pharmacological Basis of Therapeutics. McGraw-Hill, New York, 447-483.

13. Newman ME, Shalom G, Ran A et al. (2004). Chronic fluoxetineinduced desensitization of $5-\mathrm{HT}_{1 \mathrm{~A}}$ and $5-\mathrm{HT}_{1 \mathrm{~B}}$ autoreceptors: regional differences and effects of WAY-100635. European Journal of Pharmacology, 486: 25-30. 
14. Brocco M, Dekeyne A, Veiga S et al. (2002). Induction of hyperlocomotion in mice exposed to a novel environment by inhibition of serotonin reuptake. A pharmacological characterization of diverse classes of antidepressant agents. Pharmacology, Biochemistry, and Behavior, 71: 667-680.

15. Stanford JA, Currier TD \& Gerhardt GA (2002). Acute locomotor effects of fluoxetine, sertraline, and nomifensine in young versus aged Fischer 344 rats. Pharmacology, Biochemistry, and Behavior, 71: 333-340.

16. Silva SR, Futuro-Neto HA \& Pires JGP (1990). Inhibition of chlorpromazine-induced catalepsy by the $5-\mathrm{HT}_{1 \mathrm{~A}}$ ligands pindolol and buspirone in mice. Brazilian Journal of Medical and Biological Research, 23: 869-871.

17. Pires JGP, Fonseca FC, Woelffel AB et al. (1998). Evidence of interaction between fluoxetine and isosorbide dinitrate on neuroleptic-induced catalepsy in mice. Brazilian Journal of Medical and Biological Research, 31: 417-420.

18. Dell'Agnello G, Ceravolo R, Nuti A et al. (2001). SSRls do not worsen Parkinson disease: evidence from an open-label, prospective study. Clinical Neuropharmacology, 24: 221-227.

19. Prinssen EPM, Colpaert FC \& Koek W (2002). 5-HT $1 \mathrm{~A}$ receptor activation and anti-cataleptic effects: high-efficacy agonists maximally inhibit haloperidol-induced catalepsy. European Journal of Pharmacology, 453: 217-221.

20. Flugge G, Pfender D, Rudolph $S$ et al. (1999). $5 \mathrm{HT}_{1 \mathrm{~A}}$-receptor binding in the brain of cyclic and ovariectomized female rats. Journal of Neuroendocrinology, 11: 243-249. 